\title{
The role of immune cell subpopulations in the growth and rejection of TC-1/A9 tumors in novel mouse strains differing in the H2-D haplotype and NKC domain
}

\author{
MARIE INDROVÁ ${ }^{1,2}$, JOANNA ROSSOWSKA ${ }^{3}$, ELZBIETA PAJTASZ-PIASECKA ${ }^{3}$, ROMANA MIKYŠKOVÁ ${ }^{1,2}$, \\ JAN RICHTER $^{4}$, JOZEF ROSINA ${ }^{4}$, RADISLAV SEDLACEK ${ }^{1,2}$ and ANNA FIŠEROVÁ ${ }^{4,5}$ \\ ${ }^{1}$ Department of Transgenic Models of Diseases; ${ }^{2}$ Czech Centre for Phenogenomics, \\ Institute of Molecular Genetics of The Czech Academy of Sciences, 25242 Vestec, Czech Republic; \\ ${ }^{3}$ Ludwik Hirszfeld Institute of Immunology and Experimental Therapy, Polish Academy of Sciences, \\ 53-114 Wroclaw, Poland; ${ }^{4}$ Department of Health Care Disciplines and Population Protection, \\ Czech Technical University in Prague, Faculty of Biomedical Engineering, 27201 Kladno; ${ }^{5}$ Laboratory of Immunotherapy, \\ Institute of Microbiology of The Czech Academy of Sciences Prague, 14220 Prague 4, Czech Republic
}

Received September 11, 2017; Accepted December 14, 2017

DOI: $10.3892 / \mathrm{ol} .2018 .7763$

\begin{abstract}
The present study aimed to elucidate the role of cluster of differentiation (CD)8+, CD4+, natural killer (NK), and myeloid $(\mathrm{CD} 11 \mathrm{~b}+)$ cells in the course of the growth and rejection of experimental major histocompatibility complex (MHC) class I-deficient, HPV16 E6/E7-associated TC-1/A9 tumors in mice. Stable mouse lines $\left(\mathrm{F}_{30}\right)$ generated by inbreeding of Balb/c and C57BL/6 strains, which were characterized by $\mathrm{H}-2 \mathrm{Db}+\mathrm{d}-\mathrm{NK} 1.1$ neg (B6-neg) and $\mathrm{H}-2 \mathrm{Db}-\mathrm{d}+\mathrm{NK} 1.1 \mathrm{high}$ (Balb-high) phenotypes, were used for the present study. The novel strains spontaneously regressed tumors in 70-90\% of cases. Ex vivo histological analysis of the tumor microenvironment in cryosections showed an indirect correlation between the growth of the transplanted tumor (progressor vs. regressor mice) and the proportion of immunocompetent cell infiltration in the tumors. The regressor mice exhibited a higher infiltration of tumors with $\mathrm{CD} 4^{+}$and $\mathrm{CD}^{+}$cells, and in Balb-high with NK cells as well, compared with the progressors. All tumor transplants also indicated a huge infiltration of $\mathrm{CD}_{11 b^{+}}$cells, but this infiltration was not dependent on the stage of the TC-1/A9 tumor development. Depletion of individual cell subpopulations in vivo exhibited different effects on the tumor development in the two strains. Elimination of CD8-positive cells enhanced growth
\end{abstract}

Correspondence to: Dr Marie Indrová, Department of Transgenic Models of Diseases, Institute of Molecular Genetics of The Czech Academy of Sciences, Průmyslová 595, 25242 Vestec, Czech Republic

E-mail: marie.indrova@img.cas.cz

Key words: novel mouse strains, B6-neg and Balb-high mice, TC-1/A9 tumor, spontaneous tumor rejection, tumor-infiltrating cells, depletion in vivo of TC-1/A9 tumor transplants in both hybrid stains, whereas $\mathrm{CD} 4^{+}$cell depletion affected rejection of TC-1/A9 tumors in the B6-neg mice only. Depletion of NK cells with anti-asialo GM1 antibody in the Balb-high strain led to enhancement of tumor growth, which was more pronounced after depletion of the NK1.1+ $1^{+}$subpopulation. On the other hand, depletion of NK cells with anti-asialo GM1 in B6-neg mice did not affect the regression of TC-1/A9 tumor transplants, but increased the

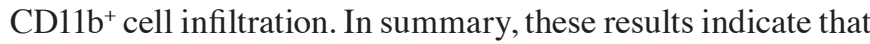
co-operation of particular subsets of immunocompetent cells is essential for the rejection of TC-1/A9 tumor transplants. In B6-neg mice, the co-operative action of $\mathrm{CD}^{+}$and $\mathrm{CD} 4^{+}$cells is required, whereas in Balb-high mice, the synergy of $\mathrm{CD} 8^{+}$ and NK1.1 $1^{+}$cells is of major importance.

\section{Introduction}

The antitumor immune response is based on the tight co-operation between the components of innate and adaptive immunity, and is strongly influenced by the active role of the tumor microenvironment manifested by immune cell suppression and selection of non-immunogenic tumor cell variants (1). In the surveillance of major histocompatibility complex class I (MHC I)-deficient tumors, natural killer (NK) cells are primarily involved, but they also participate in priming the specific, MHC I-restricted immune responses via IFN- $\gamma$ secretion leading to upregulation of MHC class I expression on tumors, potentiating the cytotoxic $\mathrm{T}$ lymphocyte-mediated response $(2,3)$.

To get deeper insight into the mechanisms playing a role in the antitumor innate and adaptive immunity, we used stable mouse hybrids of Balb/c and C57BL/6 strains of $\mathrm{H}-2 \mathrm{Db}+\mathrm{d}-\mathrm{NK} 1.1$ neg (B6-neg) and H-2Db-d+NK1.1high (Balb-high) phenotypes, differing in the H2-D haplotype and NKC domain. These novel mouse strains expressed unique features of spontaneous tumor regression in the MHC-I negative TC-1/A9 experimental model, possibly mediated by the 
involvement of NKC polymorphisms and H-2D haplotype in the effector-target cell interaction. The homozygosity in NKC domain was proved by PCR genotyping of Nkr-p1 and Ly-49 polymorphic gene families. The genes shared by Balb and B6 parental mice (i.e., Nkr-pla, Nkr-plf, Ly-49c, CD69, and Nkg2) were identified in both hybrid strains. $N k r-p l b$ and $N k r-p l c^{\text {BALB }}$ gene isoforms of Balb were present in B6-neg mice, whereas $N k r-p l d$ and $N k r-p l c^{\mathrm{B} 6}$ of $\mathrm{B} 6$ origin were present in Balb-high mice; it means that the NKC domain was inherited as a whole. Our previous results also demonstrated the higher relative distribution of CD4+ cells in B6-neg and Balb strains (4).

We found that inoculation of B6-neg mice with TC-1/A9 tumor cells led to temporal tumor growth up to days 10-12, and then the tumors started to quickly regress. In the Balb-high mice, the period of tumor growth was prolonged to 20 days, similarly to the Balb/c parental strain (4). In the prophylactic immunization experimental settings using irradiated TC-1/A9 tumor cells in C57BL/6 mice, a remarkable role of NK1.1-positive cells in the development of immunity was observed (5).

Tumor-infiltrating leukocytes (TIL) represent important, although controversial, markers associated with the clinical outcome. Their defectiveness has been attributed to various mechanisms, including inadequate antigen presentation, recruiting of inhibitory subpopulations (Treg, MDSC), or inactivation by immunosuppressive factors in the local tumor microenvironment or by signaling through co-inhibitory molecules (6-8). However, analysis of the TIL presence can provide important evidence about the antitumor immune reactions in vivo (9). The novel mouse strains can serve as a good model for elucidation of the TIL role in tumor regression.

In this communication, we examined the role of distinct subpopulations of co-operating in vivo immunocompetent cells, i.e., $\mathrm{CD}^{+}, \mathrm{CD}^{+}, \mathrm{CD} 1 \mathrm{~b}^{+}$, and $\mathrm{NK}$ cells, in the growth and rejection of TC-1/A9 tumor transplants in the newly established mouse strains. The results of in vivo experiments were completed by detailed immunohistological analysis of tumor-infiltrating leukocytes to show the relationship between depletion of particular effector cells and tumor growth in the novel mouse strains.

\section{Materials and methods}

Experimental animals. Eight-week-old inbred female C57BL/6 (B6) (Charles River Laboratories, Munich, Germany) and Balb/c (Breading Units of Animal Facility of IMG CAS, Prague, Czech Republic) mice and the newly generated mouse strains were housed under natural day/night conditions $\left(22^{\circ} \mathrm{C}, 55 \%\right.$ relative humidity) and fed on a commercial ST1 diet (Velaz, Prague, Czech Republic) ad libitum. The novel mouse strains were produced by inbreeding $\left(\mathrm{F}_{30}\right)$ of parental C57BL/6 (H2Db+H2Dd-NK1.1high) and Balb/c (H2Db-H2Dd+NK1.1neg) mice based on the NKC domain gene expression controlled by DNA analysis, H-2D haplotype and NK1.1 by cytometric phenotyping to obtain stable $\mathrm{H} 2-\mathrm{Db}-\mathrm{Dd}+\mathrm{NK} 1.1$ high and H2-Db+Dd-NK1.1neg phenotypes of Balb-high and B6-neg strains, respectively. The homozygosity in the NKC domain (NK1.1 expression) and the H2D haplotype of the novel mouse strains was continuously examined before mating (4). Breading of mice and all experimental procedures were conducted under SPF conditions in accordance with the European Convention for the Care and Use of Laboratory Animals as approved by the Czech Animal Care and Use Committee.

Tumor cells. The TC-1/A9 (H2-Db-d-) tumor cell line (10) was derived from the TC-1 cell line (obtained from the ATCC collection) developed by co-transfection of murine C57BL/6 lung cells with HPV16 E6/E7 genes and activated (G12V) by Ha-ras plasmid DNA (11). Briefly, the TC-1 cells were inoculated into mice pre-immunized with an E7 gene-based DNA vaccine and from tumors developing in a portion of the animals, cell clones with downregulated MHC class I surface expression were isolated (TID50 $=10^{4}$ tumor cells/C57BL/6 mouse, s.c.). Temporary growth of MHC class I-deficient tumor cells in syngeneic mice lead to partial re-expression of the low MHC class I due to effect of IFN- $\gamma$ and, the epigenetic mechanisms (10,12-14). The TC-1/A9 tumor cell subline, deficient in MHC class I molecules, escaped due to the selection pressure mediated by the specific immune response. The TC-1/A9 cell line was maintained in RPMI-1640 medium (Sigma-Aldrich; Merck KGaA, Darmstadt, Germany) supplemented with $10 \%$ FCS (PAN-Biotech GmbH, Aidenbach, Germany) and antibiotics. Cells were cultured at $37^{\circ} \mathrm{C}$ in humidified atmosphere, continuously tested for $\mathrm{H}-2 \mathrm{Db}$, d negativity by FACS before injection.

Flow cytometry. The efficacy of particular cell depletion from the spleens of individual mice was verified by flow cytometry using monoclonal antibodies NK1.1-APC (clone PK136), CD3-BD-Horizon V450, CD4-PerCP, CD8-APC-eFluor780, NKp46-FITC (BD Biosciences, San Jose, CA, USA or eBioscience, San Diego, CA, USA). Samples were measured in a BD LSRII flow cytometer (BD Biosciences, Franklin Lakes, NJ, USA) in a four-laser set-up (405, 488, 561 and $633 \mathrm{~nm}$ ) and data were offline-compensated and evaluated based on single-stain controls in FlowJo version 9 (Tree Star, Ashland, OR, USA). Doublet exclusion and morphology was based on forward-scatter (FSC), FSC height and side-scatter (SSC) area; propidium iodide (PI) or Hoechst33258 (BD Biosciences) was used for exclusion of non-viable cells.

In vivo depletion experiments. For in vivo depletion, monoclonal antibodies anti-CD8 (clone 2.43), anti-CD4 (clone GK1.5), anti-NK1.1 (clone PK136) (Exbio, Praha, Czech Republic) and rabbit anti-asialo GM1 polyclonal antibody (Wako Pure Chemicals Inc., Osaka, Japan) were used. The effectiveness of depletion in vivo was tracked using flow cytometric analysis. The results are summarized in Table I.

TC-1/A9 tumor cells ( $5.10^{5}$ cells) were transplanted s.c. on day 0. CD8-, CD4-, and NK1.1-positive cells were depleted with corresponding antibodies on days $-7,-5,-2,+4,+11,+18$ $(0.1 \mathrm{mg} / \mathrm{mouse}$, i. p.). For NK cell depletion, rabbit anti-asialo GM1 was applied on days $-1,0,+3,+7$ ( $0.2 \mathrm{mg} /$ mouse, i.p, $)$, according to the manufacturer's instructions. Mice were observed twice a week, Two perpendicular diameters of the tumors were measured with a caliper and the tumor size was expressed as the tumor area. Tumor area $\left(\mathrm{cm}^{2}\right)$ was determined by measurement of the largest diameter of the tumor by the 
Table I. Expression of $\mathrm{CD}^{+}, \mathrm{CD}^{+}, \mathrm{NK}\left(\mathrm{CD} 335^{+}\right)$and $\mathrm{NK} 1.1^{+}$specificities on the spleen cells of control and depleted mice with transplanted TC-1/A9 tumors (day 21).

Per cent of positive cells \pm SD

\begin{tabular}{llcccc}
\cline { 3 - 5 } Mouse strain & Cell depletion & $\mathrm{CD} 4^{+}$ & $\mathrm{CD}^{+}$ & $\mathrm{NK}\left(\mathrm{CD} 335^{+}\right)$ & NK1.1 $^{+}$ \\
\hline B6-neg & Control & $61.00 \pm 4.42$ & $38.45 \pm 4.56$ & $3.59 \pm 1.40$ & - \\
& Depleted $^{+}$ & $3.69 \pm 3.21^{\mathrm{a}}$ & $4.26 \pm 0.86^{\mathrm{a}}$ & $1.90 \pm 1.49^{\mathrm{b}}$ & - \\
Balb-high & Control & $55.58 \pm 5.33$ & $44.20 \pm 5.44$ & $3.43 \pm 1.01$ & $6.60 \pm 0.74$ \\
B6 & Depleted $^{+}$ & $0.67 \pm 0.39^{\mathrm{a}}$ & $5.28 \pm 1.05^{\mathrm{a}}$ & $1.00 \pm 0.57^{\mathrm{a}}$ & $1.02 \pm 1.20^{\mathrm{a}}$ \\
& Control & $55.76 \pm 3.87$ & $39.11 \pm 3.57$ & $3.08 \pm 0.55$ & $7.55 \pm 0.82$ \\
Balb/c & Depleted $^{+}$ & $0.51 \pm 0.43^{\mathrm{a}}$ & $1.59 \pm 0.12^{\mathrm{a}}$ & $1.88 \pm 0.89^{\mathrm{a}}$ & $0.60 \pm 0.98^{\mathrm{a}}$ \\
& Control & $66.06 \pm 5.07$ & $30.89 \pm 1.56$ & $5.68 \pm 2.17$ & - \\
\hline
\end{tabular}

CD4-positive cells, $\mathrm{CD}^{+} \mathrm{NKp} 46 / \mathrm{CD}^{+} \mathrm{CD} 8$; CD8-positive cells, $\mathrm{CD}^{+} \mathrm{NKp} 46^{-} / \mathrm{CD} 4 \mathrm{CD}^{+}{ }^{+}$; $\mathrm{NK}$ cells, $\mathrm{CD} 3{ }^{-} \mathrm{NKp} 46^{+}$; ${ }^{+} \mathrm{Corresponding} \mathrm{subpopu-}$ lations. $\mathrm{CD}$, cluster of differentiation; $\mathrm{SD}$, standard deviation. ${ }^{\mathrm{a}} \mathrm{P}<0.001$; ${ }^{\mathrm{b}} \mathrm{P}<0.05$; t-test; $\mathrm{n}=6-8$.

greatest perpendicular diameter and calculated by the formula: Tumor area $\left(\mathrm{cm}^{2}\right)=$ largest diameter $(\mathrm{cm}) \times$ perpendicular diameter $(\mathrm{cm})$. Mice were euthanized when tumors reached the maximum size $2.0 \mathrm{~cm}$ in the largest diameter. Mice with multiple tumors were excluded from the experiments. Mice were euthanized when tumors reached the maximum size of $2.0 \mathrm{~cm}$ in diameter. According to our previous experiences, the quickly growing TC-1/A9 tumors were a prerequisite of progressors. These mice were excluded from the depletion experiments to avoid false results. On day 12 , three mice (final cohorts of 6-8 mice) from each group were sacrificed; tumors were excised and used for histological analysis. From each mouse 3-4 samples of tumor tissue from the randomly selected distinct parts of the tumor were collected. The size of the tumors on the day of analysis was also recorded.

Detection of tumor-infiltrating leukocytes. According to the procedure described in (15), 5-10 $\mu \mathrm{m}$ thick tumor tissue cryosections were fixed in $4 \%$ paraformaldehyde $(30 \mathrm{~min}$ at $4^{\circ} \mathrm{C}$ ) and incubated overnight with rat anti-CD4, rat anti-CD8, rat anti-CD11b or rat anti-CD335 (NKp46) antibodies (BD Pharmingen). The slides were then washed with PBS and incubated with goat anti-rat antibody conjugated with Alexa Fluor 488 (Molecular Probes). After one-hour incubation, the slides were washed and counterstained with PI $(2 \mu \mathrm{g} / \mathrm{ml})$. All fluorophore-labeled tissue sections were analyzed using a BioRad MRC 1024 scanning confocal fluorescence microscope equipped with LaserSharp software. Cryosections of the tumor from each individual mouse were analyzed and the representative (average) sections were selected and documented in the figures.

Statistical analyses. For statistical analyses of the growth curves, analysis of variance (ANOVA) at confidence level $95 \%$ followed with Scheffe's, Tukey-Kramer and Newman-Kreuls tests from the NCSS (Number Cruncher Statistical System, Kaysville, UT, USA) statistical package was used. For statistical evaluations of the bar diagrams, Student's t-test was utilized.

\section{Results}

Inoculation of B6-neg mice with TC-1/A9 cells led to temporal tumor growth up to days 10-12, and then the tumors started to regress. In the Balb-high mice, the period of tumor growth was prolonged to 20 days, similarly to the Balb/c parental strain. The comparison of tumor transplant development is summarized in Fig. 1A and B. During the inbreeding process, $10-20 \%$ of mice displayed progressively growing tumors and were used in the experiments comparing the difference in the immune response of regressors and progressors. Parallel evaluation of the tumor cryosections on day 12 demonstrated higher infiltration of the tumor tissue by immunocompetent cells in the regressor mice. Evaluation of these samples showed an indirect correlation between the growth of tumor transplants in progressor vs. regressor mice and the infiltration with $\mathrm{CD}^{+}, \mathrm{CD}^{+}$, and NK cells. Cryosections of tumor specimens of regressor B6-neg mice showed higher infiltration by $\mathrm{CD}^{+}$and $\mathrm{CD} 8^{+}$cells. The number of $\mathrm{NK}$ and $\mathrm{CD} 11 \mathrm{~b}^{+}$cells remained unchanged (Fig. 1C). In the Balb-high regressors, increased numbers of $\mathrm{CD}^{+}, \mathrm{CD}^{+}$, as well as $\mathrm{NK}$ cells were visible. In the control settings, infiltration of TC-1/A9 tumors with immunocompetent cells in Balb (regressors' model) and B6 mice (progressors' model) was compared with the hybrid strains (Fig. 1C). Comparing the B6 and Balb parental strains, similar infiltration with $\mathrm{CD}^{+}, \mathrm{CD}^{+}$, and $\mathrm{NK}$ cells and markedly higher numbers of $\mathrm{CD} 11 \mathrm{~b}^{+}$cells in tumor specimens of B6 mice was observed.

Following the results summarized in Fig. 1, the next sets of experiments were focused on the role of $\mathrm{CD}^{+}, \mathrm{CD}^{+}$, and $\mathrm{NK}$ cells in the TC-1/A9 tumor elimination in regressor B6-neg and Balb-high mice employing in vivo depletion of particular populations. Fig. 2 shows the results of the experiments documenting the development of TC-1/A9 tumors inoculated after pretreatment of mice with anti-CD8 $\mathrm{mAb}$. The CD8 ${ }^{+}$ cells depletion enhanced growth of the TC-1/A9 tumor transplants in both hybrid strains $(\mathrm{P}<0.05$, ANOVA Fig. 2A, $\mathrm{P}<0.05-\mathrm{B} 6$-neg mice, $\mathrm{P}<0.01$-Balb-high mice, t-test, Fig. $2 \mathrm{~B}$, day 21). The analysis of tumor cryosections demonstrated that 

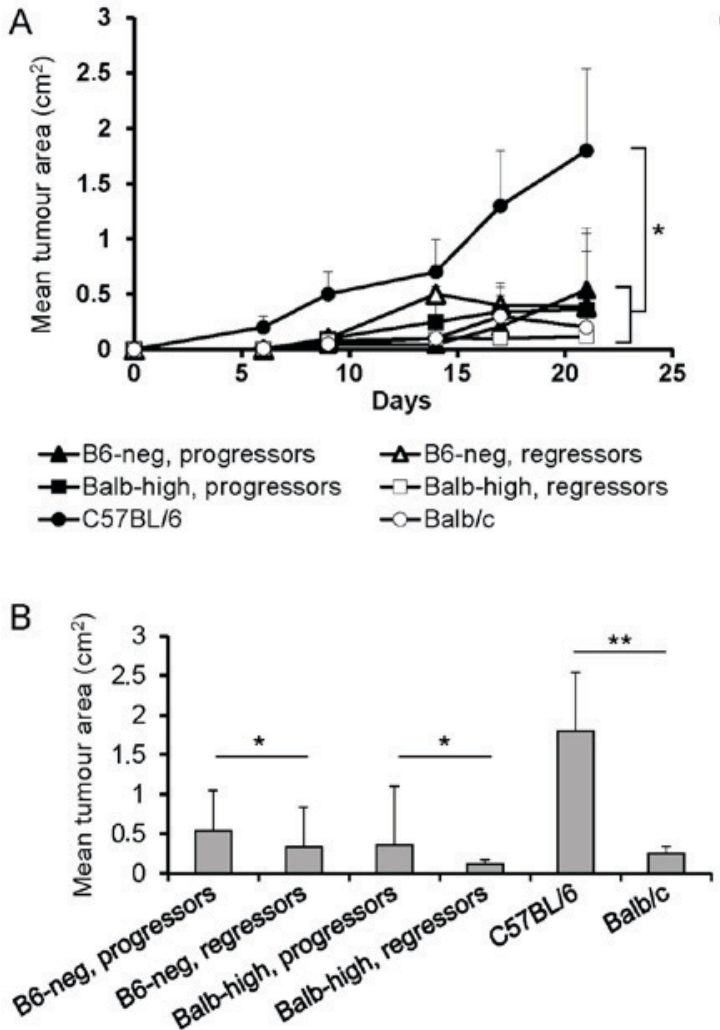

C Infiltration of tumor tissue with immunocompetent cells

Figure 1. Development of TC-1/A9 tumors in parental and hybrid mouse strains. (A) Growth of TC-1/A9 tumor transplants, $\mathrm{n}=10$, "P $<0.05$, ANOVA, B6 vs. Balb/c; ANOVA, B6-neg, progressors vs. B6-neg, regressors and Balb-high, progressors vs. Balb-high, regressors. (B) Mean tumor area of TC-1/A9 on day $21, \mathrm{n}=10 ;{ }^{* *} \mathrm{P}<0.01$, B6 vs. Balb/c; ${ }^{*} \mathrm{P}<0.05, \mathrm{~B} 6$-neg, progressors vs. B6-neg, regressors and Balb-high, progressors vs. Balb-high, regressors, t-test. (C) Infiltration of the TC-1/A9 tumor microenvironment (regressors x progressors) with immunocompetent cells (cryosections, day 12, $\mathrm{n}=3$ ). Parental strains-B6 and Balb, hybrid strains-Balb-high and B6-neg. Figure shows representative data of two experiments performed. Ex vivo tumor samples were obtained from the mice inoculated with TC-1/A9 cells in the parallel in vivo experiments.

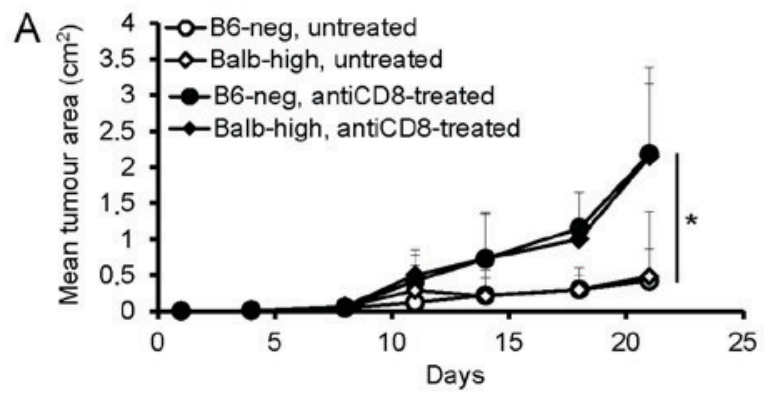

B

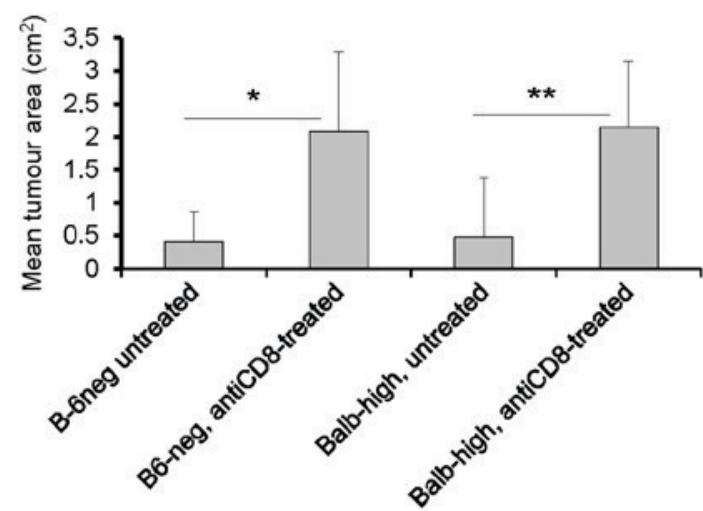

C Infiltration of tumor tissue with immunocompetent cells

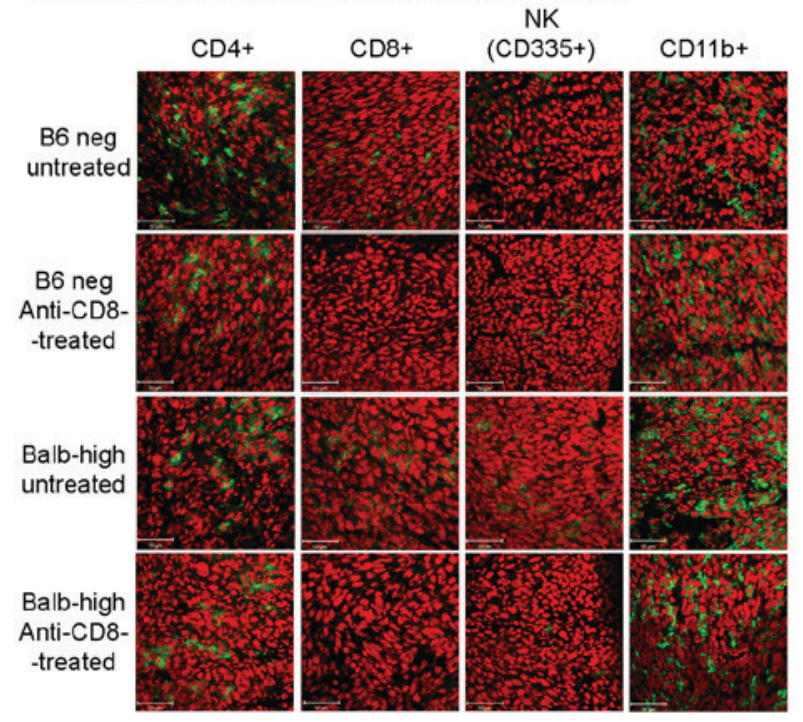

Figure 2. Enhanced growth of TC-1/A9 tumors in Balb-high and B6-neg mice after CD8 ${ }^{+}$cell depletion. (A) Growth of tumor transplants; $\mathrm{n}=6$, ${ }^{*} \mathrm{P}<0.05$, ANOVA, B6-neg, untreated vs. B6-neg, anti-CD8-treated, Balb-high untreated vs. Balb-high, anti-CD8-treated. (B) Effect of CD8-positive cell depletion on day 21, n=6; "P $<0.05$. B6-neg, untreated vs. B6-neg, anti-CD8-treated, ${ }^{* *} \mathrm{P}<0.01$ (Balb-high, untreated vs. Balb-high, anti-CD8-treated, t-test.), t-test. (C) Infiltration of tumor tissue with immunocompetent cells (cryosections), day 12, $\mathrm{n}=3$. Monoclonal antibodies: anti-CD4, anti-CD8, anti-CD11b, anti-NKp46. Ex vivo tumor samples were obtained from the mice inoculated with TC-1/A9 cells in the parallel in vivo experiments. Representative data from three independent experiments with similar results are depicted. 


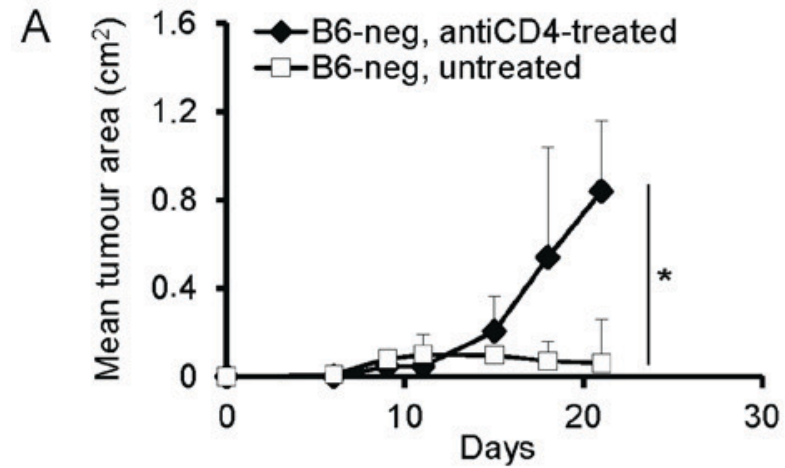

C

Infiltration of tumor tissue with immunocompetent cells
B

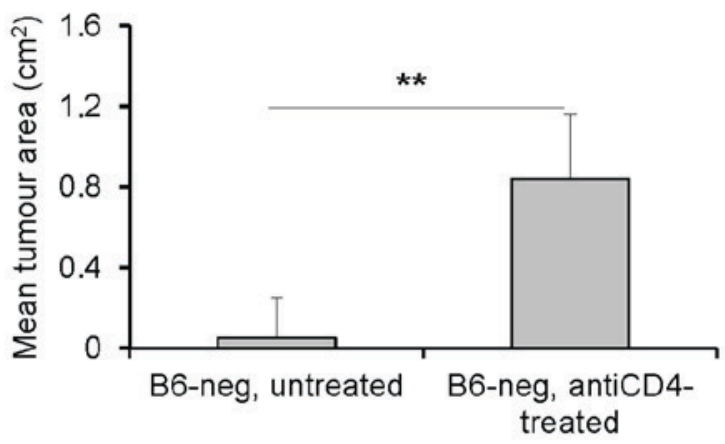

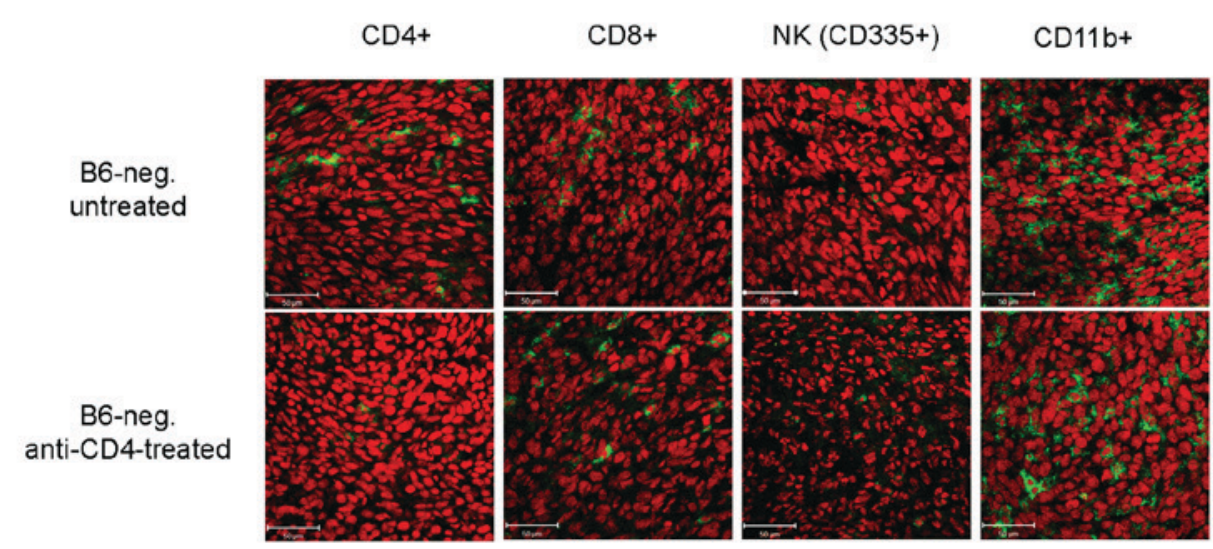

Figure 3. Enhanced growth of TC-1/A9 tumor transplants in B6-neg mice after $\mathrm{CD} 4{ }^{+}$cell depletion. (A) Growth of tumor transplants. $\mathrm{n}=6$; ${ }^{*} \mathrm{P}<0.05$, ANOVA, B6-neg, untreated vs. B6-neg, anti-CD8-treated. (B) Effect of CD4+ cell depletion on day 21, n=6; ${ }^{* *} \mathrm{P}<0.01 \mathrm{t}$-test, B6-neg, untreated vs. B6-neg, anti-CD8-treated (C) Infiltration of tumor tissue with immunocompetent cells (cryosection) on day 12 detected by monoclonal antibodies: anti-CD4, anti-CD8, anti-CD11b, anti-NKp46, n=3 Ex vivo tumor samples were obtained from the mice inoculated with TC-1/A9 cells in the parallel in vivo experiments. Representative data from three independent experiments with similar results are shown.

intraperitoneal administration of monoclonal anti-CD8 antibody diminished the infiltration of tumors by $\mathrm{CD}^{+}$cells in both novel mouse strains. Further, the number of $\mathrm{CD} 11 \mathrm{~b}^{+}$cells increased, that of $\mathrm{CD} 4^{+}$cells decreased, and the number of NK cells was not changed in B6-neg mice. In the Balb-high strain, the tumor infiltration by immunocompetent cells remained unchanged, except for missing $\mathrm{CD} 8^{+}$cells after the depletion (Fig. 2C).

Depletion of $\mathrm{CD}^{+}$cells had a different effect on the growth of tumors in B6-neg compared to Balb-high mice. Application of anti-CD4 antibodies significantly enhanced growth of the TC-1/A9 tumor transplants in B6-neg mice $(\mathrm{P}<0.05$, ANOVA, Fig. 3A, P<0.01, t-test, Fig. 3B, day 21). The effect was accompanied by decreased infiltration of tumor tissue by $\mathrm{CD} 4^{+}$cells, while other immunocompetent cells $\left(\mathrm{CD}^{+}, \mathrm{NK}, \mathrm{CD}^{1} \mathrm{~b}^{+}\right)$ were not influenced (Fig. 3C). Interestingly, elimination of $\mathrm{CD} 4^{+}$cells in Balb-high mice had no significant effect on the growth and immune cell infiltration of TC-1/A9 tumors (data not shown).

Depletion of NK cells with anti-asialo GM1 antibody in the Balb-high mice was assessed (Fig. 4) Depletion of NK cells with anti-asialo GM1 antibody in the Balb-high mice led to enhancement of TC-1/A9 tumor growth $(\mathrm{P}<0.05$, ANOVA, Fig. 4A, and $\mathrm{P}<0.05$ t-test, day 21, Fig. 4B), but not in B6-neg mice (Fig. 4A and B). The tumor growth-promoting effect was accompanied by a decrease in NK cells, increased infiltration by $\mathrm{CD}_{1} 1 \mathrm{~b}^{+}$cells, and no changes in $\mathrm{CD}^{+}$and $\mathrm{CD}^{+}$cells in both strains (Fig. 4E). Reduction of NK cells in Balb-high mice was achieved by depletion of NK1.1 $1^{+}$cells using PK 136 antibody. The depletion of NK1.1 $1^{+}$cells induced rapid growth of TC-1/A9 tumors ( $\mathrm{P}<0.05$, ANOVA, Fig. $4 \mathrm{C}$, and $\mathrm{P}<0.05$, t-test, day 21, Fig. 4D). These results, together with the accompanied diminishing of NK1.1-positive cells infiltration (Fig. 4F) have proved that the NK1.1 $1^{+}$subpopulation plays an important role in the TC-1/A9 tumor rejection (Fig. 4F). The effectiveness of depletion of the respective cells was proved by FACS analysis of splenocytes on day 12 post TC-1/A9 inoculation, which showed good results in the case of $\mathrm{CD} 8^{+}$and $\mathrm{CD} 4^{+}$cells. The NK cell depletion was generally limited when anti-asialo GM1 was used compared to the results obtained with the PK 136 antibody in the Balb-high strain (Table I). We can conclude that NK cells in the NK1.1-negative strain (B6-neg) do not influence the TC-1/A9 regression process, but take part in the regulation of the infiltration of the tumor microenvironment by $\mathrm{CD}_{11 b^{+} \text {cells. }}$

\section{Discussion}

Stable mouse hybrids of Balb/c and C57BL/6 strains, B6-neg and Balb-high, differing in the NKC domain and H2-D haplotype, were used for getting insight into the participation of $\mathrm{CD}^{+}, \mathrm{CD}^{+}, \mathrm{CD} 1 \mathrm{~b}^{+}$, and $\mathrm{NK}$ cell subpopulations in the 


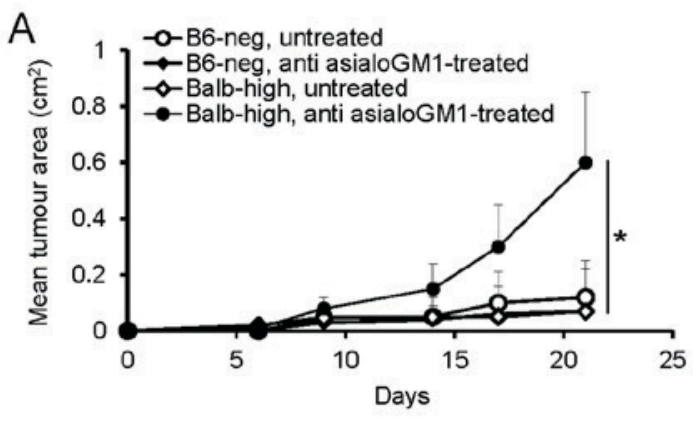

$\mathrm{B}$

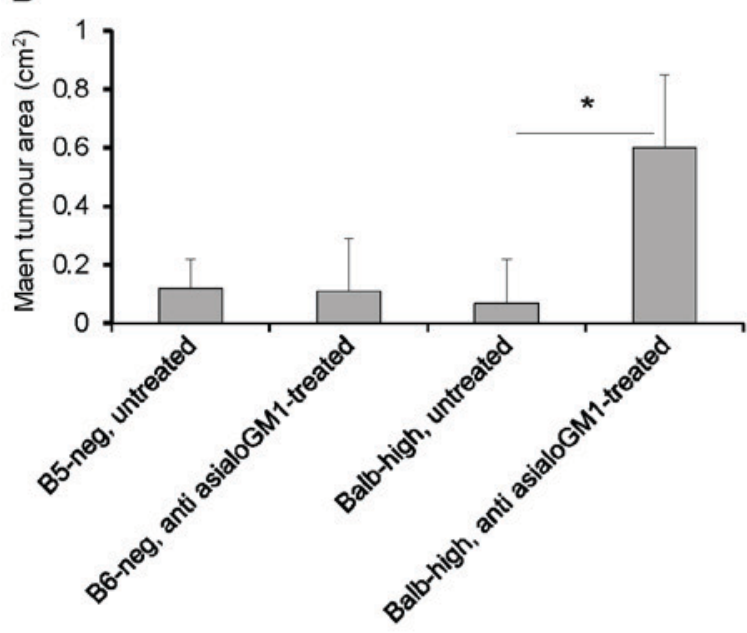

C

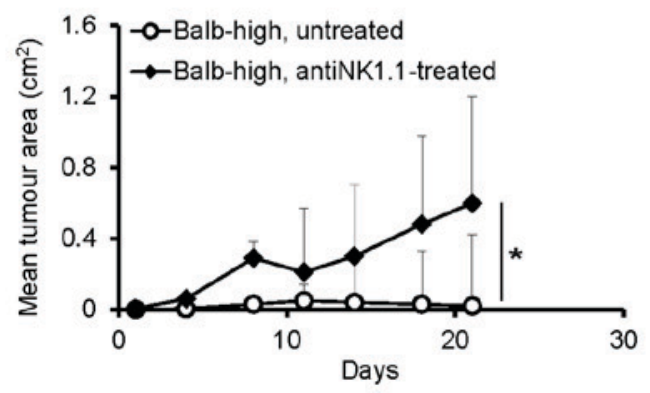

D

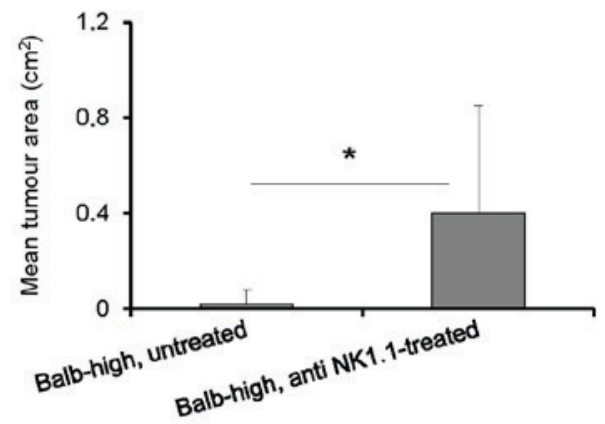

$\mathrm{E}$

Infiltration of tumor tissue with immunocompetent cells

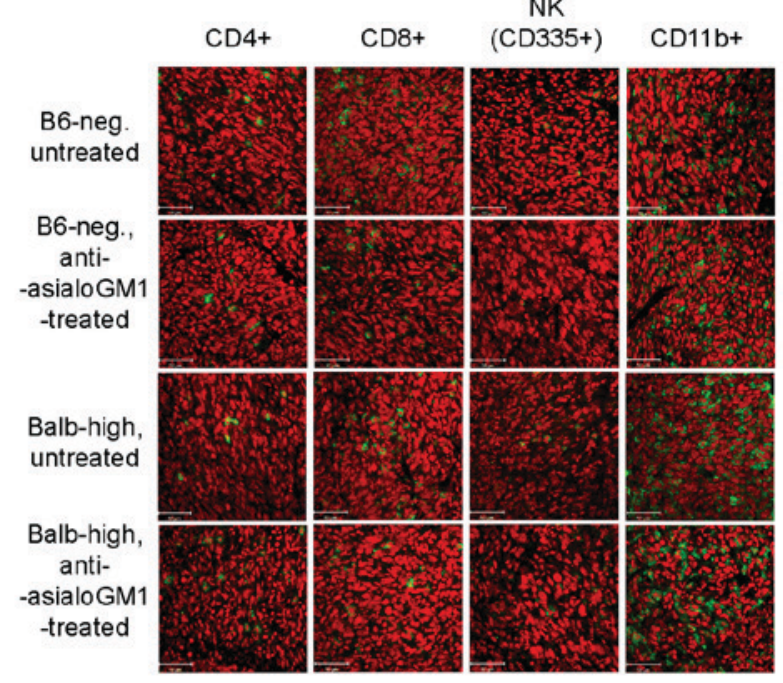

$\mathrm{F}$

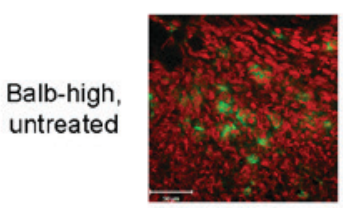

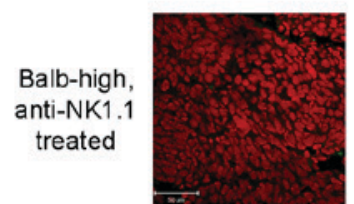

Figure 4. (A-F) Depletion of NK cells in TC-1/A9-inoculated Balb-high and B6-neg mice by polyclonal rabbit anti-asialo-GM1 (A, B and E) and monoclonal anti-NK1.1 (PK136) antibody (C, D and F). Effect of NK cell depletion (A) on the growth of tumor transplants. n=6, ANOVA, B6-neg, untreated, vs. B6-neg, anti asialoGM1-treated. "P<0.05, ANOVA, Balb-high, untreated vs. Balb-high, anti asialoGM1-treated. (B) Effect of anti asialoGM1 antibody on the tumor size on day 21, t-test, B6-neg untreated, vs. B6-neg, anti asialoGM1-treated; ${ }^{*} \mathrm{P}<0.05$ t-test, Balb-high untreated vs. Balb-high, anti asialoGM1-treated. (E) Infiltration of tumor tissue with immunocompetent cells (cryosection) on day 12 was detected by monoclonal antibodies: anti-CD4, anti-CD8, anti-CD11b, anti-NKp46, n=3. (C) Depletion of NK1.1 ${ }^{+}$cells in Balb-high mice by PK136 antibody enhanced the growth of TC-1/A9 tumor transplants. $\mathrm{n}=6$; " $\mathrm{P}<0.05$, ANOVA, Balb-high, untreated vs. Balb-high, antiNK1.1-treated. (D) Effect of NK1.1 $1^{+}$cell depletion on the size of tumors was in correlation with enhanced tumor growth. "P<0.05, t-test, Balb-high, untreated, vs. Balb-high, antiNK1.1-treated. (F) Cryosections of tumor specimens, day 12, n=3. Ab: anti-NK1.1 (PK 136); representative data of three independent experiments are shown. Ex vivo tumor samples were obtained from the mice inoculated with TC-1/A9 cells in the parallel in vivo experiments. Representative data of three independent experiments with similar results are shown.

rejection of MHC class I-deficient, HPV16 E6/E7-associated TC-1/A9 tumors. The results presented here indicate the essential role of $\mathrm{CD}^{+} \mathrm{T}$ cells, as well as of in vivo co-operation of $\mathrm{CD}^{+}, \mathrm{CD}^{+}$and $\mathrm{CD} 1 \mathrm{~b}^{+}$cells with $\mathrm{NK}$ cells, during the process of tumor rejection. However, the engagement of particular cells was different in the two hybrid strains. In B6-neg mice, co-operation of $\mathrm{CD}^{+}$and $\mathrm{CD} 4^{+}$cells is required, whereas in Balb-high mice, mainly $\mathrm{CD}^{+}$and $\mathrm{NK}\left(\mathrm{NK} 1.1^{+}\right)$ cells are important.

The TC-1/A9 tumor displayed higher infiltration of leukocytes, which was probably associated with the MHC-I deficiency of TC-1/A9 cells that does not correlate with the in vitro cytotoxic effector function of spleen cells in B6 mice (6). In our experimental settings, the in vivo depletion of $\mathrm{CD}^{+}, \mathrm{CD}^{+}$, or NK1.1 ${ }^{+}$cells led to elimination of these cells from both the tumor tissue and spleen, resulting in significant enhancement of the TC-1/A9 tumor growth.

The antitumor immune response, based on the tight co-operation between the components of innate and adaptive immunity, is also strongly influenced by the active role of the tumor microenvironment manifested by immunosuppression and selection of non-immunogenic tumor cell variants (1). The presence or lack of infiltrating immunocompetent cells (TILs) in the tumor tissue is considered one of the key characteristics 
and predictive factors of tumor regression or expansion. In the neoplastic process, the tumor microenvironment, which is largely regulated by inflammatory cells, is an indispensable participant fostering the migration, survival and proliferation of TILs. However, the frequent functional defectiveness of TILs has been attributed to various mechanisms, including inadequate antigen-presenting and/or costimulatory capacity of tumor cells leading to $\mathrm{T}$ cell ignorance or anergy and production of immune suppressive factors by the tumors (16).

The important role of $\mathrm{CD} 8^{+} \mathrm{T}$ cells responding to antigens presented by MHC I molecules could be diminished by partial renewal of the $\mathrm{H} 2-\mathrm{Db}$ marker on the tumor cell surface under the pressure induced by the growing tumor transplants in B6 and B6-neg mice (14) (Indrová, unpublished). In our study, we found that after elimination of $\mathrm{CD} 8^{+}$cells, the $\mathrm{CD} 4^{+}$cell infiltration increased in the tumor tissue. Although $\mathrm{CD} 4^{+}$ $\mathrm{T}$ cells along with $\mathrm{CD} 8^{+} \mathrm{T}$ cells represent the majority of $\mathrm{T}$ lymphocytes, they can differentiate into specific subpopulations mediating the immune response through secretion of specific cytokines. However, depending on the cytokine milieu in the tumor microenvironment, they play dual roles: They may activate or suppress the immune reactions $(17,18)$.

The results obtained after NK cell in vivo depletion also indicate a relevant role for NK cells in the development and growth of TC-1/A9 tumor transplants. NK cells also participate in priming specific, MHC I-restricted immune responses via IFN- $\gamma$ secretion leading to up-regulation of MHC class I expression on tumor cells. This process can diminish the surveillance of (MHC I)-deficient tumors because it influences the lytic activity of cytotoxic $\mathrm{T}$ lymphocytes $(1,3)$. For NK cell depletion, two types of antibodies were used, polyclonal anti-asialo GM1 and monoclonal anti-NK1.1 (PK136), which are commonly used to elucidate the in vivo functions of NK cells in mice. Anti-asialo GM1-mediated NK cell depletion is effective in a variety of mouse strains, whereas anti-NK1.1-mediated NK cell depletion acts only in certain strains such as B6 but not in strains lacking the NK1.1 allotype, for example Balb. Of note, the expression of asialo-GM1 is not strictly confined to NK cells among hematopoietic cells and is detected on a subpopulation of NKT, $\mathrm{CD} 8^{+} \mathrm{T}$, and $\gamma \delta \mathrm{T}$ cells and some activated form of $\mathrm{CD} 4^{+} \mathrm{T}$ cells, macrophages, and eosinophils under certain experimental conditions. At least NKT cells, characterized by expression of $\mathrm{T}$ cell and NK cell receptors, are important immune regulators that can either promote or suppress antitumor immunity and could play a role in the growth and regression of TC-1/A9 tumors (19-21). Nevertheless, anti-asialo GM1-mediated NK cell depletion still remains a powerful tool to analyze the in vivo functions of NK cells (22). The anti-asialo GM1 antibody administration or elimination of NK1.1 cells with anti-NK1.1 antibody (PK136) resulted in significant enhancement of tumor growth in the Balb-high strain. On the other hand, the anti-asialo GM1 antibody administration did not affect the tumor growth in the B6-neg tumor strain. These findings, indicating the crucial role of NK1.1 $1^{+} \mathrm{NK}$ cell subpopulation in the development and growth of transplanted TC-1/A9 tumors, correspond to those obtained in our laboratory in the B6 mouse model, which showed an important role of NK1.1 $1^{+}$cells in the development of protective immunity against TC-1/A9 tumors (5). Activity of NK cells is downregulated by Tregs, having important role in the resulting anti-tumor immunity $(12,23)$. NK cells contribute also to adaptive immunity through interaction with dendritic cells (DC). NK-DC communication regulates $\mathrm{T}$ cell-mediated immune responses and DC itself has been considered in adjuvant therapeutic modality of tumors. Such effect could be direct, T cell-mediated, or indirect when APC were treated. (24). Further, Zalli et al showed that neural regulation of immune response, namely through -2 adrenergic receptor, which potentiate NK killing (25). This is in correlation with our preliminary results using differential expression (DE) analysis of RNA isolated from splenocytes of tumor regressors in comparison with progressor mice that showed the involvement -2 adrenergic receptors. These findings need to be verified by further molecular analysis.

In this study, the increased infiltration of tumors with

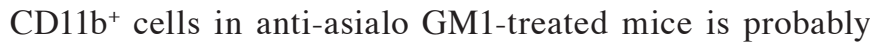
related to the regulatory role of NK cells in the monocyte (MDSC) number (26).

In both newly established mouse strains, the high infiltration of CD11b+ monocytes was confirmed. CD11b, an integrin family member, is considered to be a pan-macrophage marker, which is expressed on a huge variety of leukocytes and can be upregulated on activated cells irrespective of their naive expression status. CD11b is also a marker for myeloid-derived suppressor cells (MDSC). MDSCs are a heterogeneous population of undifferentiated cells characterized in mice by markers of monocytes (CD11b) and neutrophils (Gr-1). Among leukocyte-infiltrating tumors, MDSCs represent one of the key players mediating immunosuppression (27-31). Therefore, the number of CD11b+ infiltrating cells did not itself exhibit any effect on the development, growth and rejection of TC-1/A9 tumors in novel mouse strains.

Taken together, these results extend the findings published earlier (4) and provide more detailed information about the changes in the repertoire of immune cells during the development of transplanted TC-1/A9 (H2-Db-d-) tumors in the novel mouse strains differing in the H-2D haplotype and NKC domain. We have demonstrated the important role of NK1.1+ NK cells in the development, growth and rejection of TC.1/A9 tumors and in the regulation of antitumor immunity in general.

\section{Acknowledgements}

The present study was supported by the grant 14-10100S awarded by the Czech Science Foundation, in part by the Ministry of Education, Youth and Sports (MEYS, LM2015040; Czech Centre for Phenogenomics), Academy of Sciences of the Czech Republic (RVO 68378050), by project 'BIOCEV-Biotechnology and Biomedicine Centre of the Academy of Sciences and Charles University' (CZ.1.05/1.1.00/02.0109) and 'Higher quality and capacity for transgenic models' (CZ.1.05/2.1.00/19.0395) funded by the Ministry of Education, Youth and Sports and the European Regional Development Fund, and, in part, by the Bilateral Agreement between Polish Academy of Sciences and the Czech Academy of Sciences. The authors are grateful to Milan Reiniš, PhD, for reviewing the manuscript, Mrs. Renáta Turečková for skillful technical assistance, and Mrs. Šárka Takáčová for editorial help. 


\section{References}

1. Swann JB and Smyth MJ: Immune surveillance of tumors. J Clin Invest 117: 1137-1146, 2007.

2. Xu D, Gu P, Pan PY, Li Q, Sato AI and Chen SH: NK and CD8+ $\mathrm{T}$ cell-mediated eradication of poorly immunogenic B16-F10 melanoma by the combined action of IL-12 gene therapy and 4-1BB costimulation. Int J Cancer 109: 499-506, 2004.

3. Ghiringhelli F, Apetoh L, Housseau F, Kroemer G and Zitvogel L: Links between innate and cognate tumor immunity. Curr Opin Immunol 19: 224-231, 2007.

4. Fišerová A, Richter J, Čapková K, Bieblová J, Mikyšková R, Reiniš $\mathrm{M}$ and Indrová $\mathrm{M}$ : Resistance of novel mouse strains different in MHC class I and the NKC domain to the development of experimental tumors. Int J Oncol 49: 763-772, 2016.

5. Indrová M, Símová J, Bieblová J, Bubeník J and Reinis M: NK1.1+ cells are important for the development of protective immunity against MHC I-deficient, HPV16-associated tumours. Oncol Rep 25: 281-288, 2011.

6. Indrová M, Bieblová J, Rossowska J, Kuropka P, Pajtasz-Piasecka E, Bubeník J and Reinis M: HPV 16-associated tumours: IL-12 can repair the absence of cytotoxic and proliferative responses of tumour infiltrating cells after chemotherapy. Int J Oncol 34: 173-179, 2009.

7. Mikyšková R, Indrová M, Vlková V, Bieblová J, Šímová J, Paračková Z, Pajtasz-Piasecka E, Rossowska J and Reiniš M: DNA demethylating agent 5-azacytidine inhibits myeloid-derived suppressor cells induced by tumor growth and cyclophosphamide treatment. J Leukoc Biol 95: 743-753, 2014.

8. Kodumudi KN, Siegel J, Weber AM, Scott E, Sarnaik AA and Pilon-Thomas S: Immune checkpoint blockade to improve tumor infiltrating lymphocytes for adoptive cell therapy. PLoS One 11: e $0153053,2016$.

9. Yu P and Fu YX: Tumor-infiltrating T lymphocytes: Friends or foes? Lab Invest 86: 231-245, 2006.

10. Smahel M, Síma P, Ludvíková V, Marinov I, Pokorná D and Vonka V: Immunisation with modified HPV16 E7 genes against mouse oncogenic TC-1 cell sublines with downregulated expression of MHC class I molecules. Vaccine 21: 1125-1136, 2003.

11. Lin KY, Guarnieri FG, Staveley-O'Carroll KF, Levitsky HI, August JT, Pardoll DM and Wu TC: Treatment of established tumors with a novel vaccine that enhances major histocompatibility class II presentation of tumor antigen. Cancer Res 56: 21-26, 1996.

12. Mikysková R, Bubeník J, Vonka V, Smahel M, Indrova M, Bieblová J, Símová J and Jandlová T: Immune escape phenotype of HPV16-associated tumours: MHC class I expression changes during progression and therapy. Int J Oncol 26: 521-527, 2005.

13. Símová J, Bubeník J, Bieblová J, Rosalia RA, Fric J and Reinis M: Depletion of T (reg) cells inhibits minimal residual disease after surgery of HPV16-associated tumours. Int J Oncol 29: 1567-1571, 2006.

14. Manning J, Indrova M, Lubyova B, Pribylova H, Bieblova J, Hejnar J, Simova J, Jandlova T, Bubenik J and Reinis M: Induction of MHC class I molecule cell surface expression and epigenetic activation of antigen-processing machinery components in a murine model for human papilloma virus 16-associated tumours. Immunology 123: 218-227, 2008.

15. Rossowska J, Pajtasz-Piasecka E, Szyda A, Zietara N and Duś D: Tissue localization of tumor antigen-loaded mouse dendritic cells applied as an anti-tumor vaccine and their influence on immune response. Folia Histochem Cytobiol 45: 349-355, 2007.
16. Hadrup S, Donia M and Thor Straten P: Effector CD4 and CD8 $\mathrm{T}$ cells and their role in the tumor microenvironment. Cancer Microenviron 6: 123-133, 2013.

17. Luckheeram RV, Zhou R, Verma AD and Xia B: CD4 ${ }^{+} \mathrm{T}$ cells: Differentiation and functions. Clin Dev Immunol 2012: 925135, 2012.

18. Koretzky GA: Multiple roles of CD4 and CD8 in T cell activation. J Immunol 185: 2643-2644, 2010.

19. Smyth MJ, Crowe NY and Godfrey DI: NK cells and NKT cells collaborate in host protection from methylcholanthrene-induced fibrosarcoma. Int Immunol 13: 459-463, 2001.

20. Bendelac A, Savage PB and Teyton L: The biology of NKT cells. Annu Rev Immunol 25: 297-336, 2007.

21. Símová J, Indrová M, Bieblová J, Mikysková R, Bubeník J and Reinis M: Therapy for minimal residual tumor disease: Beta-galactosylceramide inhibits the growth of recurrent HPV16-associated neoplasms after surgery and chemotherapy. Int J Cancer 126: 2997-3004, 2010.

22. Nishikado H, Mukai K, Kawano Y, Minegishi Y and Karasuyama H: NK cell-depleting anti-asialo GM1 antibody exhibits a lethal off-target effect on basophils in vivo. J Immunol 186: 5766-5771, 2011.

23. Tomar MS, Kumar S, Kumar S, Gautam PK, Singh RK, Verma PK, Singh SP and Acharya A: NK cell effector functions regulation by modulating nTreg cell population during progressive growth of Dalton's lymphoma in mice. Immunol Invest 11: 1-17, 2017.

24. da Cunha A, Antoniazi Michelin M and Cândido Murta EF: Phenotypic profile of dendritic and T cells in the lymph node of Balb/C mice with breast cancer submitted to dendritic cells immunotherapy. Immunol Lett 177: 25-37, 2016.

25. Zalli A, Bosch JA, Goodyear O, Riddell N, McGettrick HM, Moss $\mathrm{P}$ and Wallace GR: Targeting $\beta 2$ adrenergic receptors regulate human $\mathrm{T}$ cell function directly and indirectly. Brain Behav Immun 45: 211-218, 2015

26. Sato Y, Shimizu K, Shinga J, Hidaka M, Kawano F, Kakimi K, Yamasaki S, Asakura M and Fujii SI: Characterization of the myeloid-derived suppressor cell subset regulated by NK cells in malignant lymphoma. Oncoimmunology 4: e995541, 2015.

27. Gabrilovich DI and Nagaraj S: Myeloid-derived suppressor cells as regulators of the immune system. Nat Rev Immunol 9: 162-174, 2009.

28. Mikyšková R, Indrová M, Símová J, Bieblová J, Bubeník J and Reiniš M: Genetically modified tumour vaccines producing IL-12 augment chemotherapy of HPV16-associated tumours with gemcitabine. Oncol Rep 25: 1683-1689, 2011.

29. Gabrilovich DI, Ostrand-Rosenberg S and Bronte V: Coordinated regulation of myeloid cells by tumours. Nat Rev Immunol 12: 253-268, 2012

30. Umansky V and Sevko A: Tumor microenvironment and myeloid-derived suppressor cells. Cancer Microenviron 6: 169-177, 2013.

31. Sevko A and Umansky V: Myeloid-derived suppressor cells interact with tumors in terms of myelopoiesis, tumorigenesis and immunosuppression: Thick as thieves. J Cancer 4: 3-11, 2013.

This work is licensed under a Creative Commons Attribution-NonCommercial-NoDerivatives 4.0 International (CC BY-NC-ND 4.0) License. 